\title{
Article \\ Effects of Dietary L-Carnitine Supplementation on Platelets and Erythrogram of Dairy Cows with Special Emphasis on Parturition
}

\author{
Susanne Ursula Kononov ${ }^{1,2}$, Jennifer Meyer ${ }^{1}$, Jana Frahm ${ }^{1, * \mathbb{D}}$, Susanne Kersten ${ }^{1} \mathbb{D}_{\text {, Jeannette Kluess }}{ }^{1}$, \\ Ulrich Meyer $^{1}$, Korinna Huber ${ }^{2}$ and Sven Dänicke ${ }^{1}$ (D) \\ 1 Institute of Animal Nutrition, Friedrich-Loeffler-Institut, Federal Research Institute for Animal Health, \\ Bundesallee 37, 38116 Braunschweig, Germany; Susanne.Kononov@uni-hohenheim.de (S.U.K.); \\ Jennifer.Meyer@fli.de (J.M.); Susanne.Kersten@fli.de (S.K.); Jeannette.Kluess@fli.de (J.K.); \\ Ulrich.Meyer@fli.de (U.M.); Sven.Daenicke@fli.de (S.D.) \\ 2 Institute of Animal Science, Functional Anatomy of Livestock, University of Hohenheim, Fruwirthstrasse 35, \\ 70593 Stuttgart, Germany; Korinna.Huber@uni-hohenheim.de \\ * Correspondence: Jana.Frahm@fli.de; Tel.: +49-531-58044-142
}

check for updates

Citation: Kononov, S.U.; Meyer, J.; Frahm, J.; Kersten, S.; Kluess, J.; Meyer, U.; Huber, K.; Dänicke, S. Effects of Dietary L-Carnitine Supplementation on Platelets and Erythrogram of Dairy Cows with Special Emphasis on Parturition. Dairy 2021, 2, 1-13. https: / /dx.doi.org/dairy2010001

Received: 29 October 2020

Accepted: 15 December 2020

Published: 22 December 2020

Publisher's Note: MDPI stays neutral with regard to jurisdictional claims in published maps and institutional affiliations.

Copyright: (c) 2020 by the authors. Licensee MDPI, Basel, Switzerland. This article is an open access article distributed under the terms and conditions of the Creative Commons Attribution (CC BY) license (https: / / creativecommons.org / licenses/by/4.0/).
Abstract: During late gestation and early lactation, many proliferative processes and metabolic adaptions are involved in homeorhesis. An adjusted supply of oxygen is a precondition for an optimized cellular energy metabolism whereby erythrocytes play a central role. Endogenous L-carnitine modulates the mitochondrial fatty acid utilization for generating adenosine triphosphate (ATP). As it might be insufficient around calving due to increased need, L-carnitine supplementation is frequently recommended. Thus, the present study addressed the interplay between the red hemogram, platelets, oxidative stress indices, and L-carnitine supplementation of dairy cows around calving. German Holstein cows were assigned to a control $(n=30)$ and an L-carnitine group $(n=29,25 \mathrm{~g}$ of rumenprotected L-carnitine per cow and per day), and blood samples were taken from day 42 ante partum (ap) until day 110 postpartum (pp), with a higher sampling frequency during the first three days pp. The time courses of the erythrogram parameters reflected the physiological adaptations to the oxygen need without being influenced by L-carnitine supplementation. Erythrocytic antioxidative enzymatic defence paralleled the relative development of polycythemia ap, while non-enzymatic total plasma antioxidative capacity continuously increased pp. In contrast to erythrocytes, the platelet counts of the L-carnitine supplemented cows varied at significantly higher levels. This can be interpreted as a result of a membrane-stabilizing effect of L-carnitine.

Keywords: L-carnitine; dairy cow; hematology; erythrocytes; erythrogram; platelets; calving; parturition

\section{Introduction}

The transition phase of the cow constitutes a special feature of the production cycle [1,2]. This time is defined as the period from three weeks before until three weeks after calving, and it is metabolically and physiologically challenging for dairy cows [3]. The associated changes are reflected in hormonal, immunological, and hematological status [1,4]. Furthermore, hematological alterations are a part of these adaptations. Interestingly, although the platelets (PLTs) and the erythrogram are also part of a complete hematological profile, they have not been the focus of earlier studies.

Erythrocytes (RBCs) represent the most abundant population of blood cells and are crucial for body homeostasis. RBCs contain no nucleus and no mitochondria, and have a purely anaerobic energy metabolism $[5,6]$. Their primary task is the transport of oxygen. To this end, they consist mainly of the iron-containing protein hemoglobin (HGB) [7], and have a special membrane composition. As oxygen-transporting cells, RBCs are consequently exposed to oxidative stress. In order to still maintain their functionality, RBCs possess a highly efficient antioxidant system involving enzymes, such as superoxide dismutase (SOD) 
and glutathione peroxidase (GPx). PLTs are dynamic blood particles whose primary function is hemostasis and the control of bleeding [8], which is of special importance immediately after delivering the calf. Furthermore, the PLTs contribute to inflammatory processes, microbial host defense, wound healing, angiogenesis, and remodeling [8]. Mean platelet volume (MPV) and plateletcrit (PCT), the indices of PLTs, are biomarkers for the change of platelets in form and activation [8-10]. PLTs are able to intrinsically produce oxygen radicals, which are likely to play an important role in the mechanism of PLT activation [11]. To control the oxidative stress, PLTs also have a number of antioxidant defenses, like SOD or GPx. In the time of parturition, which goes along with increased inflammatory processes, the enhanced production of ROS produces increased oxidative stress [12,13].

Besides the oxygen supplied by RBCs, further factors are necessary and need to be adjusted to the actual requirements for generating energy. In particular, an up-regulation of bovine hepatic genes involved in carnitine synthesis and L-carnitine uptake was demonstrated within the first week after calving [14], and might indicate a critical time frame for energy metabolism. L-carnitine plays a major role in the cycle of energy production in the mitochondria by transporting activated long-chain fatty acids through the inner mitochondrial membrane into the mitochondrial matrix, where $\beta$-oxidation takes place $[14,15]$. L-carnitine is also involved in the regeneration of acetyl coenzyme A [16]. It is able to protect the antioxidant enzymes from further peroxidative damage [16]. With its derivatives, e.g., acetyl-L-carnitine, it is able to protect cell membranes from ROS-induced damage [16]. Furthermore, L-carnitine can stabilize membranes and prevent lipid oxidation, which was detected in in vitro and in vivo experiments for the RBCs and PLTs [17-20].

Because the antioxidant supply decreases around parturition due to reduced feed intake and lactation, a dietary supply with L-carnitine could help to improve the oxidative situation [21,22], with possible consequences for hematological traits.

Hence, the aim of the study was to clarify the hypothesis that the RBCs, PLTs, and related indices of dairy cows are differently affected by L-carnitine supplementation over the transition period, with a special focus on parturition.

\section{Materials and Methods}

\subsection{Animal Experiment and Design}

The experiment was performed at the experimental station of the Institute of Animal Nutrition, Friedrich-Loeffler-Institut (FLI), Braunschweig, Germany, in accordance with the German Animal Welfare Act concerning the protection of experimental animals, and was approved by Lower Saxony State Office for Consumer Protection and Food Safety (LAVES, Oldenburg, Germany) (AZ33.19-42502-04-16/2378). A detailed description of the experimental design was given in Meyer et al. [23]. In brief, 59 pluriparous and clinically healthy German Holstein dairy cows were equally allocated, based on body weight (568-1008 kg), body condition score (2.5-4.75), and number of lactations (2-5 lactations), to one of two feeding groups, a control (CON, $n=30)$ and an L-carnitine supplemented group (CAR, $n=29$ ). The experiment started 42 days $(\mathrm{d})$ before anticipated parturition and ended at $\mathrm{d} 110$ in milk. Both groups were fed with a partial mixed ration diet (PMR), with or without a supplementation of $125 \mathrm{~g}$ of rumen-protected L-carnitine product (Carneon 20 Rumin-Pro, Kaesler Nutrition GmbH, Cuxhaven, Germany), corresponding to a daily L-carnitine intake of $25 \mathrm{~g}$ per cow and per day. For all cows, the composition of roughage remained unchanged during the experiment (70\% maize silage, $30 \%$ grass silage). From $42 \mathrm{~d}$ ap until one $\mathrm{d}$ after parturition, the animals received a PMR of $80 \%$ roughage and $20 \%$ concentrate. After parturition, the concentrate was increased up to $50 \%$ within $14 \mathrm{~d}$. Thereafter, the PMR diets were based on the recommendation of nutrient and energy supply of the Society of Nutrition Physiology (GfE). PMR was offered by feed-weigh troughs (RIC, System Insentec B.V., Marknesse, The Netherlands), while the pelleted concentrate was administered by concentrate feeding stations (Insentec B.V., Marknesse, The Netherlands). The individual water and feed intake were continuously recorded automatically using an ear tag detection system and were described in more details by Meyer et al. [23]. In order to 
ensure the individual L-carnitine intake, it was included in the feed concentrate. To balance the fat content of the L-carnitine product, CON obtained a fat product (BergerFat F-100 HP, Berg+Schmidt GmbH \& Co. KG, Hamburg, Germany), which is equivalent to that used for the rumen protection of the L-carnitine. Water was offered ad libitum.

\subsection{Sample Collection}

Blood from Vena jugularis externa was collected into ethylenediaminetetraacetic acid (EDTA) containing serum tubes at $\mathrm{d} 42,14,7,3$, and 1 before calving and $\mathrm{d} 7,14,21,28,42$, 56, 100, and 110 after parturition. Additionally, blood samples were taken $0.5,1,2,3,4,6,9$, $12,24,48$, and $72 \mathrm{~h}$ after parturition, whereby samples were collected via an indwelling catheter (Vena jugularis externa) within the first $12 \mathrm{~h}$ pp. All blood samples were processed within $2 \mathrm{~h}$ after collection.

\subsection{Laboratory Methods}

\subsubsection{Hematology}

Hematological measurements were performed in whole blood (10 mL EDTA tubes, SARSTEDT AG \& Co. KG, Nümbrecht, Germany) using the automated analyzer Celltac- $\alpha$ (MEK 6450, Nihon Kohden, Qinlab Diagnostik, Weichs, Germany). The red blood cell count included: erythrocyte count (RBC), hematocrit (HCT), hemoglobin concentration (HGB), mean corpuscular volume (MCV), mean corpuscular hemoglobin (MCH), mean corpuscular hemoglobin concentration (MCHC), and red cell distribution width (RDW). The platelet related parameters included: platelet count (PLT), plateletcrit (PCT), mean platelet volume (MPV), and platelet distribution width (PDW).

Hemoglobin derivatives oxyhemoglobin (oxy-HGB), carboxyhemoglobin (carboxyHGB), methemoglobin (met-HGB), and deoxyhemoglobin (deoxy-HGB) were determined in heparinized blood ( $2 \mathrm{~mL}$ syringe, Werfen, Kirchheim, Germany). Immediately after, the sampling measurement was performed using an automated blood gas analyzer (GEM Premier 4000, Werfen, Kirchheim, Germany).

\subsubsection{Antioxidant Enzyme Activities}

Glutathione peroxidase (GPx) and superoxide dismutase (SOD) activities were measured in erythrocyte lysate. For this purpose, $2 \mathrm{~mL}$ of EDTA blood were mixed with $10 \mathrm{~mL}$ of cold distilled water and centrifuged $\left(10 \mathrm{~min}, 10,000 \times \mathrm{g}, 4^{\circ} \mathrm{C}\right)$. The resulting supernatant was stored at $-80{ }^{\circ} \mathrm{C}$ until further analysis. HGB concentration in erythrocyte lysate was determined using an automatic analyzer (Celltac- $\alpha$ MEK 6450, Nihon Kohden, Qinlab Diagnostik, Weichs, Germany).

GPx activity was measured with a commercial Ransel glutathione peroxidase assay (Randox Laboratories, Crumlin, UK) based on the method of Paglia and Valentine [24]. Measurements were performed in duplicate according to the manufacturer's protocol; however, volumes were adjusted to fit a 96-well format. The decrease in NADPH was analyzed by measuring the absorbance at $340 \mathrm{~nm}$ and $37{ }^{\circ} \mathrm{C}$ at two time points in the reaction's linear range on a TECAN infinite M200 plate reader (Tecan Infinite ${ }^{\circledR} 200$, Tecan Group Ltd., Männedorf, Switzerland). Activity of SOD was identified using a commercial Ransod superoxide dismutase assay (Randox Laboratories, Crumlin, UK) in duplicate. The assay was conducted according to the manufacturer's protocol; however, these volumes were also adjusted correspondingly to fit a 96-well format. The activity of GPx as well as SOD was expressed as U per grams of HGB.

\subsubsection{Ferric Reducing Ability of Plasma (FRAP)}

The ferric reducing ability was measured in plasma in duplicates. For this, EDTA blood was centrifuged at $1950 \times g$ for $15 \mathrm{~min}$ and the top layer, representing the plasma, was stored at $-80{ }^{\circ} \mathrm{C}$ until analysis.

The ferric reducing ability of plasma (FRAP) was measured according to the method of Benzie and Strain [25], with some in-house modifications relating to sample volume 
and dilution using a 96-well format. The reduction of ferric to ferrous ion at low $\mathrm{pH}$ by non-enzymatic antioxidants in blood formed a blue colored ferrous-tripyridyltriazine complex. Change in absorbance was measured after $15 \mathrm{~min}$ of incubation $\left(37^{\circ} \mathrm{C}\right)$ at $593 \mathrm{~nm}$ using a plate reader (Tecan Infinite ${ }^{\circledR}$ 200, Tecan Group Ltd., Männedorf, Switzerland). A calibration curve of $\mathrm{Fe}^{2+}$ was prepared and used for calculation. Results are expressed as $\mu \mathrm{M}$.

\subsubsection{Derivatives of Reactive Oxygen Metabolites (dROM)}

The amount of free oxygen radicals in plasma samples was determined by measuring the concentrations of derivatives of reactive oxygen metabolites (dROMs), using a colorimetric assay according to the method of Regenhard et al. [26]. To this end, heparinized blood was centrifuged at $1950 \times g$ for $15 \mathrm{~min}$. The examination was then done in triplicate. Samples were incubated in $10 \mu \mathrm{L}$ volumes together with $10 \mu \mathrm{L}$ of chromogen $(0.37 \mathrm{M}$ $\mathrm{N}, \mathrm{N}$-Diethyl-1,4phenylendiammomiumsulphate, Merck, Darmstadt, Germany), $10 \mu \mathrm{L}$ of $6 \mathrm{mM} \mathrm{FeSO}_{4}$ (VWR International, Radnor, PA, USA), and $970 \mu \mathrm{L}$ of acetate buffer $(0.01 \mathrm{M}$, pH 5.0, AppliChem, Darmstadt, Germany) for 120 min at $37^{\circ} \mathrm{C}$. Standard $\mathrm{H}_{2} \mathrm{O}_{2}$ was used instead of $10 \mu \mathrm{L}$ sample volume, and for the generation of a standard curve in a range of $0.4 \mu \mathrm{g} / \mathrm{mL}(0.013 \mathrm{mM})$ to $4 \mu \mathrm{g} / \mathrm{mL}(0.13 \mathrm{mM})$ of $\mathrm{H}_{2} \mathrm{O}_{2}$. After cooling for $10 \mathrm{~min}$ in an ice bath, the absorption was determined with a plate reader (Tecan Infinite ${ }^{\circledR}$ 200, Tecan Group Ltd., Männedorf, Switzerland) at $505 \mathrm{~nm}$. Results are expressed as mM.

\subsection{Statistical Analysis}

Statistical analysis was performed using the PROC MIXED procedure of the SAS software package (Version 9.4, SAS Institute Inc., Cary, NC, USA) with the restricted maximum likelihood method. The model included group (G; CON or CAR), time (T; experimental day relative to parturition), and the interaction between $G \times T$ as fixed effects. The values from $\mathrm{d} 42$ ap were considered as co-variates. Variance components were used as the covariance structure, since they exhibited the lowest Akaike information criterion (AICC). Statistical differences were declared significant at $p \leq 0.05$. Additionally, differences of means were considered to be significant at $p$-values $\leq 0.05$ using Tukey's adjusted t-test. All results were presented as least square (LS) means and pooled standard errors (PSE) were stated.

\section{Results}

\subsection{Erythrogram}

All variables of the erythrogram changed over time $\left(p_{\mathrm{T}}<0.001\right)$, but were unaffected by group or by any interaction.

RBCs (Figure 1a) showed a constant increase by 13\% from d 42 ap, peaking significantly at $4 \mathrm{~h} \mathrm{pp}$ and decreasing thereafter until $\mathrm{d} 21 \mathrm{pp}$ where it reached lower levels than initially. It then remained constant until d $110 \mathrm{pp}$. The HCT (Figure 1b) increased consistently from the beginning of the trial and peaked significantly $4 \mathrm{~h} \mathrm{pp}$. Thereafter, it decreased until the end of the trial and fell below the initial level on $42 \mathrm{~d}$ pp. The RDW (Figure 1c) increased significantly from d 42 ap up to d 14 ap. It remained at this level until d $56 \mathrm{pp}$. Afterwards, it decreased significantly until d 110 pp. The MCV (Figure 1d) increased by $4 \%$ from d 42 ap until $0.5 \mathrm{~h} \mathrm{pp}$, where it reached a plateau and remained constant until d 14 pp. After d 14 pp, it declined until the end of the trial. The MCH (Figure 1e) remained on the initial level up to $72 \mathrm{~h} \mathrm{pp}$ and rose significantly between $\mathrm{d} 3$ and $7 \mathrm{pp}$ by $3 \%$. After $28 \mathrm{~d} \mathrm{pp}$, it decreased until d $100 \mathrm{pp}$. The MCHC (Figure 1f) decreased by $5 \%$ from d 42 ap until $2 \mathrm{~h} \mathrm{pp}$. Then it remained at the same level until $72 \mathrm{~h} \mathrm{pp}$. Subsequently, it started to increase by $5 \%$ at $7 \mathrm{~d}$ pp, and remained thereafter on this level until d $110 \mathrm{pp}$. 


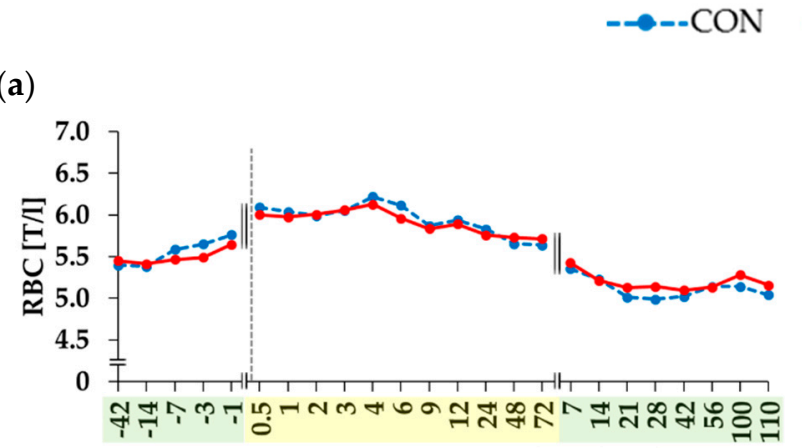

Time relative to parturition in days and hours

(c)

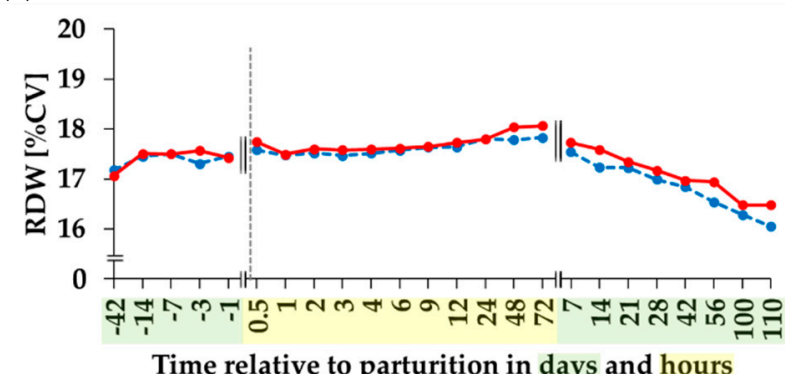

(e)

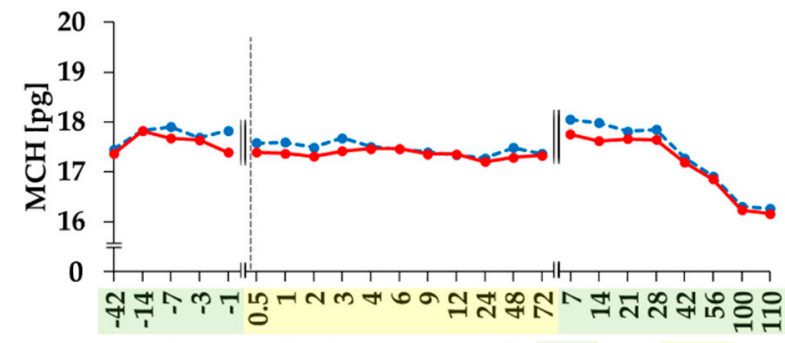

Time relative to parturition in days and hours (b)

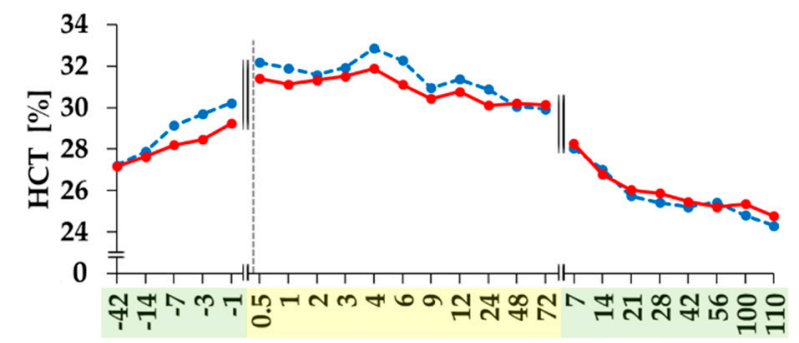

Time relative to parturition in days and hours

(d)

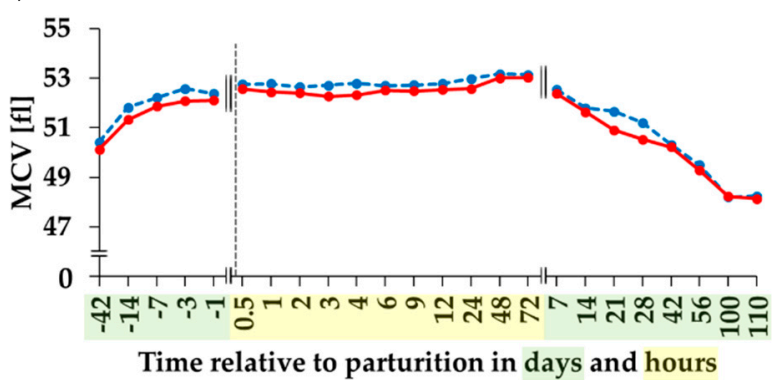

(f)

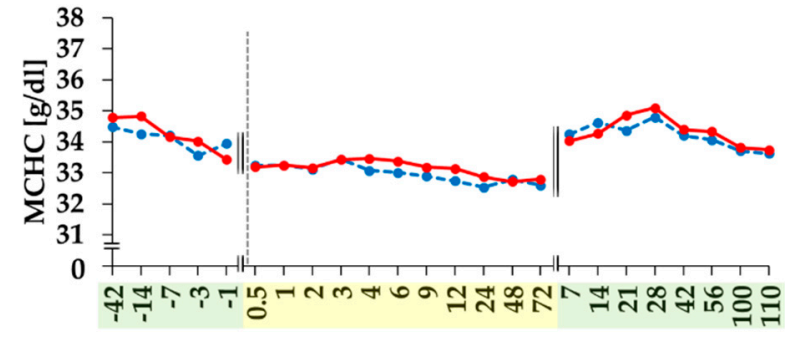

Time relative to parturition in days and hours

\begin{tabular}{ccccc}
\hline & \multicolumn{3}{c}{$p$-Values } & \\
\cline { 2 - 4 } & Group & Time & Group x Time & PSE 1 \\
\hline RBC & 0.998 & $<\mathbf{0 . 0 0 1}$ & 0.659 & 0.033 \\
HCT & 0.184 & $<\mathbf{0 . 0 0 1}$ & 0.634 & 0.187 \\
RDW & 0.703 & $<\mathbf{0 . 0 0 1}$ & 0.895 & 0.106 \\
MCV & 0.395 & $<\mathbf{0 . 0 0 1}$ & 0.877 & 0.193 \\
MCH & 0.310 & $<\mathbf{0 . 0 0 1}$ & 0.970 & 0.066 \\
MCHC & 0.141 & $<\mathbf{0 . 0 0 1}$ & 0.719 & 0.070 \\
\hline
\end{tabular}

Figure 1. Effects of dietary L-carnitine on erythrogram of dairy cows fed a diet supplemented either with (CAR) or without (CON) L-carnitine from six weeks before until 15 weeks after calving. (a) Total erythrocyte count (RBC). (b) Hematocrit (HCT). (c) Red blood cell distribution width (RDW). (d) Mean corpuscular volume (MCV). (e) Mean corpuscular hemoglobin $(\mathrm{MCH})$. (f) Mean corpuscular hemoglobin concentration (MCHC). Data are shown as least square means. ${ }^{1}$ Pooled standard error. Bold $p$-values indicate significant values.

\subsection{Platelets}

The PLT, PCT, and MPV showed significant interaction between group and time $\left(p_{\mathrm{GxT}}<0.001\right)$, whereas the PDW was unaffected by time, group, or their interaction.

The PLTs (Figure 2a) of both groups remained on the initial level until $1 \mathrm{~d}$ ap. Afterwards, the number of PLTs in CON increased by $11 \%$ within $24 \mathrm{~h}$ before calving to 
$0.5 \mathrm{~h}$ pp. The number of PLTs of CAR increased by $13 \%$ from $\mathrm{d} 3$ ap until $0.5 \mathrm{~h}$ pp. CON remained on this level until d $7 \mathrm{pp}$, and increased thereafter significantly by $25 \%$ until $\mathrm{d} 21 \mathrm{pp}$. CAR remained on its initial level until d $21 \mathrm{pp}$ and then increased by $13 \%$ until d 28 pp. Afterwards, both groups decreased until the end of the trial. In both groups, PCT (Figure $2 \mathrm{~b}$ ) remained on the initial level until $7 \mathrm{~d} \mathrm{pp}$. From $\mathrm{d} 7 \mathrm{pp}$ onwards, CON increased by $30 \%$ until d $21 \mathrm{pp}$, and CAR by $23 \%$ until d $28 \mathrm{pp}$. PCT decreased subsequently in both groups until the end of the trial. The MPV (Figure 2c) fluctuated over time and showed a significant interaction between group and time based on a crossover interaction of the course of both groups over time.

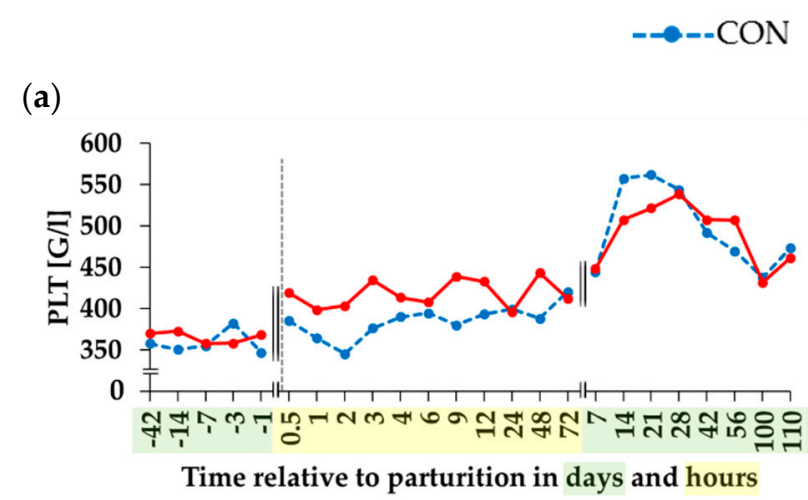

(c)

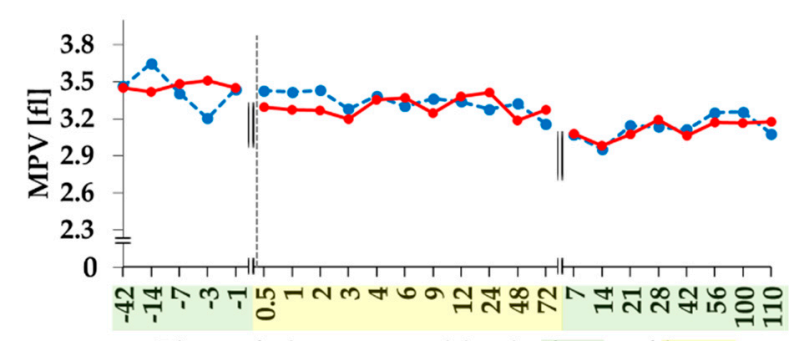

Time relative to parturition in days and hours

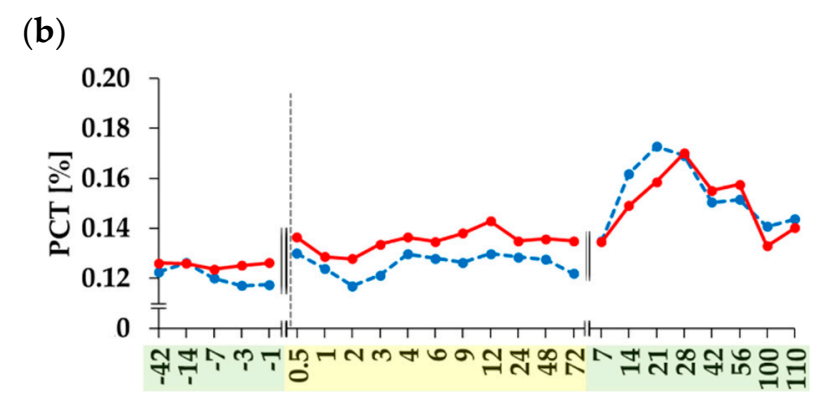

Time relative to parturition in days and hours

(d)

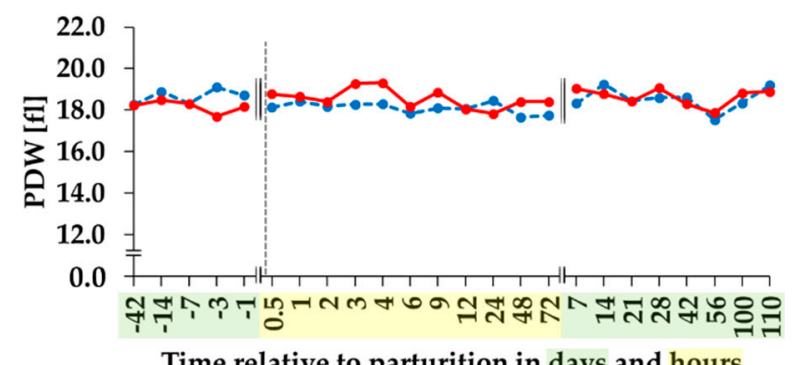

\begin{tabular}{ccccc}
\hline & \multicolumn{3}{c}{$p$-Values } & \\
\cline { 2 - 4 } & Group & Time & Group x Time & PSE $^{1}$ \\
\hline PLT & 0.389 & $<\mathbf{0 . 0 0 1}$ & $\mathbf{0 . 0 3 9}$ & 0.693 \\
PCT & 0.394 & $<\mathbf{0 . 0 0 1}$ & $\mathbf{0 . 0 1 8}$ & 0.002 \\
MPV & 0.806 & $<\mathbf{0 . 0 0 1}$ & $\mathbf{0 . 0 3 7}$ & 0.028 \\
PDW & 0.478 & 0.163 & 0.475 & 0.129 \\
\hline
\end{tabular}

Figure 2. Effects of dietary L-carnitine on platelet count and platelet-related parameters in dairy cows starting six weeks before until 15 weeks after calving. (a) Platelet count (PLT). (b) Plateletcrit (PCT). (c) Mean platelet volume (MPV). (d) Platelet distribution width (PDW). Data are shown as least square means. ${ }^{1}$ Pooled standard error. Bold $p$-values indicate significant values.

\subsection{Hemoglobin and Derivatives of Hemoglobin}

HGB and its derivatives were all affected by time $\left(p_{\mathrm{T}}<0.001\right)$, except carboxy-HGB and met-HGB, which were neither influenced by group nor time, or the interaction of these two factors.

The percentage of HGB (Figure 3a) increased consistently from the beginning of the trial and peaked significantly $4 \mathrm{~h} \mathrm{pp}$. Thereafter, it decreased until the end of the trial and fell below the initial level after $42 \mathrm{~d}$ pp. Oxy-HGB (Figure $3 \mathrm{~b}$ ) increased by $12 \%$ from $\mathrm{d} 7 \mathrm{ap}$ until $1 \mathrm{~h} \mathrm{pp}$ and remained unchanged until $72 \mathrm{~h} \mathrm{pp}$. Afterwards, it steadily decreased until the end of the trial. Deoxy-HGB (Figure 3c) decreased significantly by $6 \%$ from $\mathrm{d} 7$ ap to 
$1 \mathrm{~h} \mathrm{pp}$ and remained on the same level until $72 \mathrm{~h} \mathrm{pp}$. This was followed by a significant increase by $13 \%$ until the end of the experimental period.

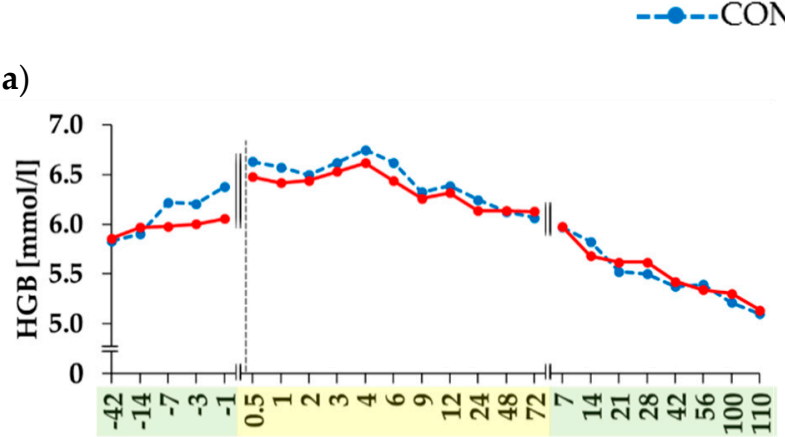

Time relative to parturition in days and hours

(c)

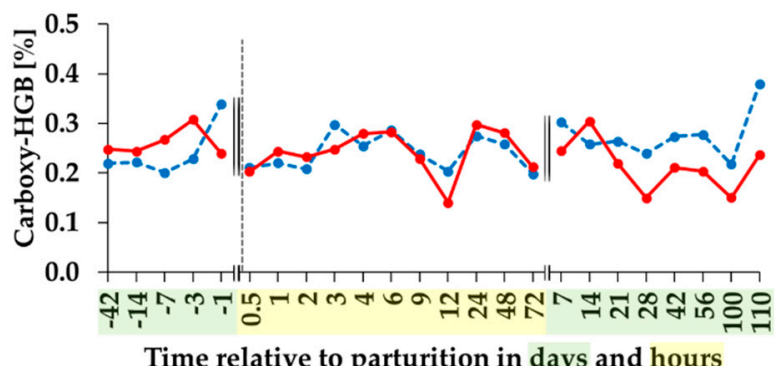

(e)

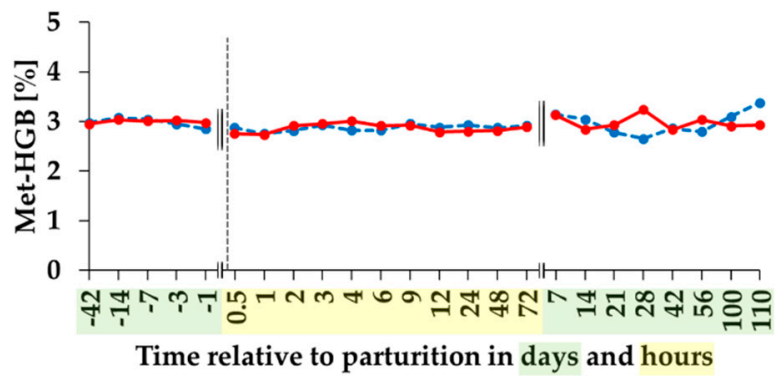

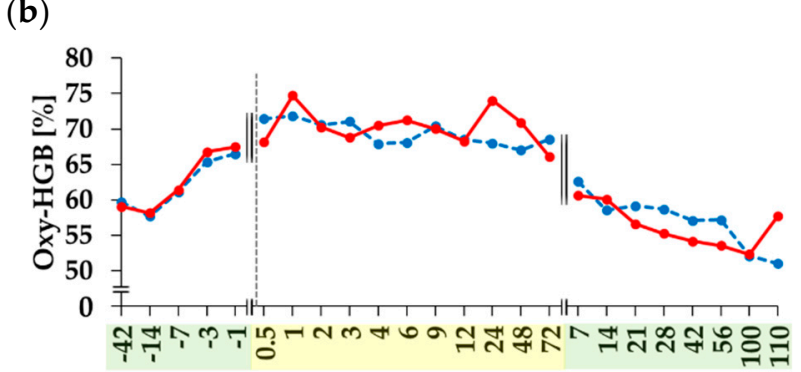

Time relative to parturition in days and hours

(d)

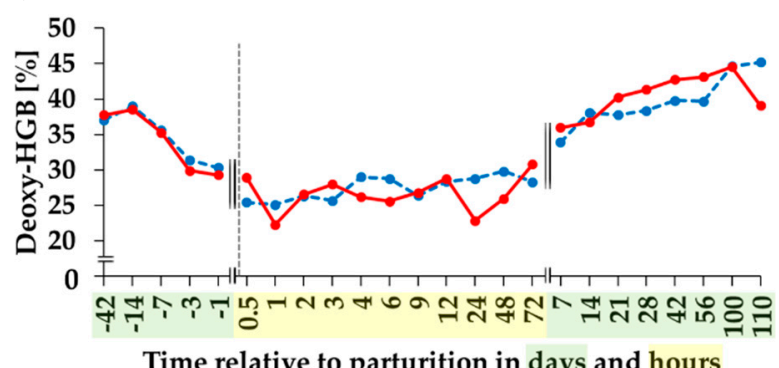

\begin{tabular}{lcccc}
\hline & \multicolumn{4}{c}{$p$-Values } \\
\cline { 2 - 4 } & Group & Time & Group x Time & PSE $^{1}$ \\
\hline HGB & 0.346 & $<\mathbf{0 . 0 0 1}$ & 0.407 & 0.036 \\
Oxy-HGB & 0.755 & $<\mathbf{0 . 0 0 1}$ & 0.536 & 0.724 \\
Carboxy-HGB & 0.419 & 0.355 & 0.960 & 0.015 \\
Deoxy-HGB & 0.769 & $<\mathbf{0 . 0 0 1}$ & 0.589 & 0.722 \\
Met-HGB & 0.922 & 0.060 & 0.089 & 0.033 \\
\hline
\end{tabular}

Figure 3. Effects of dietary L-carnitine on hemoglobin and its derivatives in dairy cows fed a diet supplemented with (CAR) or without (CON) L-carnitine from six weeks before until 15 weeks after calving. (a) Hemoglobin (HGB). (b) Oxyhemoglobin (Oxy-HGB). (c) Carboxyhemoglobin (Carboxy-HGB). (d) Deoxyhemoglobin (Deoxy-HGB). (e) Methemoglobin (Met-HGB). Data are shown as least square means. ${ }^{1}$ Pooled standard error. Bold $p$-values indicate significant values.

\subsection{Indicators for the Oxidative and Antioxidative Status}

All antioxidant enzymes changed over time $\left(p_{\mathrm{T}}<0.001\right)$, but were unaffected by group or by the interaction of time and group.

SOD activity (Figure 4a) increased in both groups by $29 \%$ from d 42 ap until one d before calving. After calving, the enzyme activity decreased and remained on this lower level until d 56. Activity of GPx (Figure $4 \mathrm{~b}$ ) increased by $22 \%$ from d 42 ap to $\mathrm{d} 14$ ap and remained unchanged until d 1 ap. Directly after calving $(0.5 \mathrm{~h} \mathrm{pp})$, GPx activity was $31 \%$ lower than on $\mathrm{d} 1$ ap and remained on this level until d $110 \mathrm{pp}$. FRAP (Figure 4c) remained on the initial level until d 14 pp. After d 14 pp, it increased by $36 \%$ until the end of the trial. $\mathrm{dROM}$ (Figure $4 \mathrm{~d}$ ) remained on the initial level until $9 \mathrm{~h}$ pp and increased thereafter by $27 \%$ until d $14 \mathrm{pp}$. From d $14 \mathrm{pp}$, it decreased significantly by $25 \%$ until d $100 \mathrm{pp}$ and remained on this level until the end of the trial. 


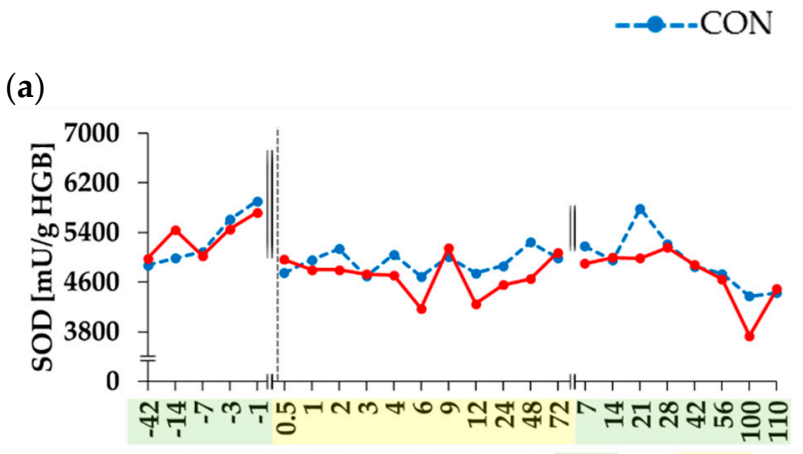

Time relative to parturition in days and hours

(c)

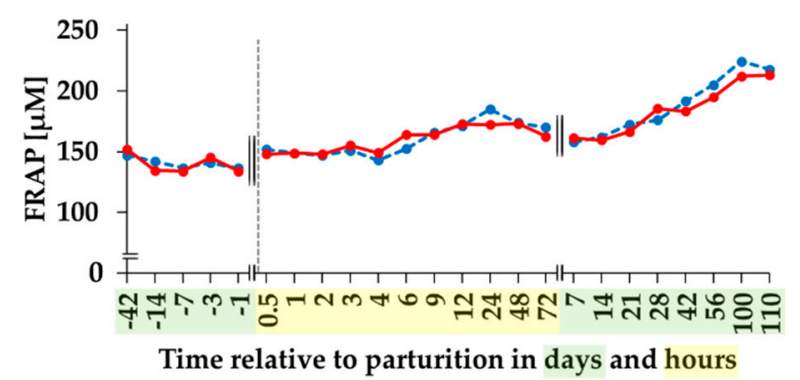

(b)

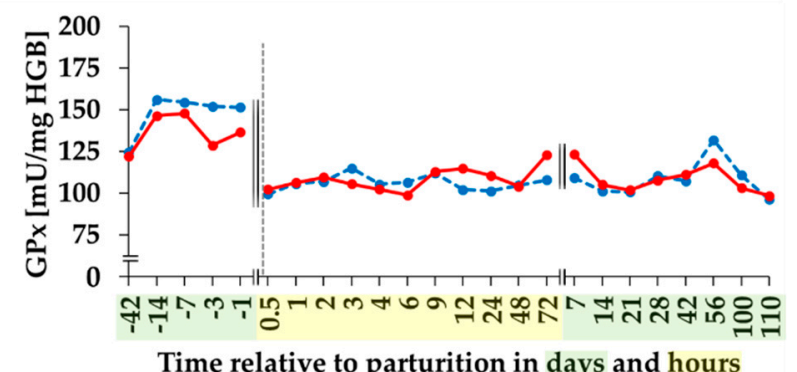

(d)

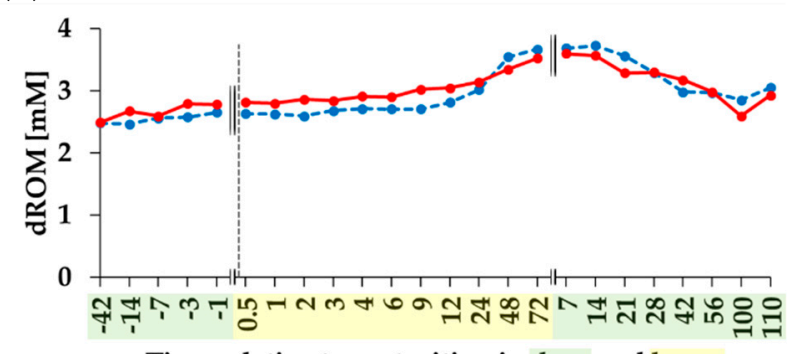

Time relative to parturition in days and hours

\begin{tabular}{ccccc}
\hline & \multicolumn{3}{c}{$p$-Values } & \\
\cline { 2 - 4 } & Group & Time & Group x Time & PSE ${ }^{1}$ \\
\hline SOD & 0.173 & $<\mathbf{0 . 0 0 1}$ & 0.540 & 79.135 \\
GPx & 0.863 & $<\mathbf{0 . 0 0 1}$ & 0.781 & 2.355 \\
FRAP & 0.477 & $<\mathbf{0 . 0 0 1}$ & 0.331 & 1.891 \\
dROM & 0.654 & $<\mathbf{0 . 0 0 1}$ & 0.150 & 1.555 \\
\hline
\end{tabular}

Figure 4. Effects of dietary L-carnitine on indicators for the oxidative and antioxidative status in dairy cows fed diet supplemented with (CAR) or without (CON) L-carnitine from six weeks before until 15 weeks after calving. (a) Erythrocytic superoxide dismutase (SOD) measured in erythrocyte lysate. (b) Erythrocytic glutathione peroxidase (GPx) measured in erythrocyte lysate. (c) Ferric reducing ability of plasma (FRAP). (d) Derivatives of reactive oxygen metabolites (dROM) measured in plasma. Data are shown as least square means. ${ }^{1}$ Pooled standard error. Bold $p$-values indicate significant values.

\section{Discussion}

Placentation, fetal development, mammogenesis, lactogenesis, and galactopoiesis are physiological processes which are characterized, amongst others, by cell proliferation and tissue expansion [27], which also requires angiogenesis in order to enable erythrocytes to deliver oxygen for generating the necessary energy. Increasing oxygen demand of the uterus and fetus, particularly during the last trimester of gestation, and of the mammary gland throughout lactogenesis and galactopoiesis, can be met by an increased blood flow and an enhanced oxygen transport capacity. Augmented blood flow can be managed via an adjustment of the cardiac output as a result of an increased respiratory activity. During this process of adaptation, both local and systemic hypoxia emerges, which triggers the induction of the hypoxia-inducible factor 1 (HIF), a transcription factor that is involved in the regulation of a number of cellular processes. Amongst others, HIF triggers angiogenesis and erythropoiesis through induction of erythropoietin (EPO), which in turn acts on bone marrow to release progenitors of RBC [28-31]. Mammary blood flow correlates positively with mammary oxygen uptake and with milk yield in goats and cows [32,33]. Moreover, oxygen consumption by portal-drained viscera and by the liver rises at the beginning of lactation aimed at supporting the generally upregulated nutrient and energy metabolism 
in this period and particularly of gluconeogenesis as a precondition for lactose and milk synthesis [34].

The specific role of L-carnitine in this process becomes obvious considering that the increased oxygen supply to tissues requires an upregulated and optimized cellular metabolism to generate ATP. On one hand, L-carnitine contributes to an effective fatty acid utilization, and on the other hand, it functions as an antioxidant, which is important in the view that increased cellular oxygen utilization also triggers ROS formation. Previous results demonstrated that a supplementation of $25 \mathrm{~g}$ of rumen-protected L-carnitine per cow and per d resulted in an efficiently increased L-carnitine level in blood, higher milk yield in early lactation, and higher milk fat percentages in the first week of lactation [23]. However, the additive failed to support the cows' recovery from parturition and to improve the energy status pp. Although the gross energy metabolism of the cows remained nearly uninfluenced [23], the questions to be answered by the present investigations were whether the putative homeorhetic adaptations of erythrocytes and PLT were modified by L-carnitine addition and whether they were paralleled by systematic adjustments of oxidative and antioxidative status.

Temporal progression of almost all presented indices of the erythrogram illustrated adaptive processes before and directly pp and in a long-term course without any effect of L-carnitine supplementation.

In particular, besides erythrocytes, all other variables of the erythrogram showed higher values seven weeks prior to calving when compared to d 110 in milk, suggesting an already upregulated erythropoiesis at this particular stage of fetal development. The further increase in these variables excepting MCHC until or shortly after parturition supported the discussed view that late exponential fetal development and mammogenesis triggered erythropoiesis through local oxygen deficiency induced HIF and EPO expression. The increase in RDW in this time period further supported the view of a stimulated erythropoiesis, which was reflected by a peripheral increase in erythrocyte size variation, also known as anisocytosis. Based on the stronger increase in HCT compared to $\mathrm{RBC}$, the volume of individual erythrocytes (MCV) markedly increased, which might also have contributed to the increased RDW. At the same time, the HGB content of individual erythrocytes $(\mathrm{MCH})$ remained constant, whereby the concurrent decline in the HGB concentration in erythrocytes (MCHC) becomes explainable. Taking the ap period collectively, a relative polycythemia developed in this time, which was paralleled by a relative macrocytosis, along with an increasing capacity of HGB for binding oxygen. All of these events seemed to be directed to supporting the increasing needs for oxygen without any impact of supplemented L-carnitine.

Related to calving itself, Moretti et al. [35] and Tharwat et al. [36] described that RBC, HGB, and HCT increased to a maximum level within $12 \mathrm{~h}$ pp. Olmos et al. [37] reported about the highest level of RBC in dairy cows between $0-5 \mathrm{~d}$ pp without exact specification of time related to calving. The maximum HGB concentrations were described within the first hours after parturition $[35,37,38]$. A similar progression could be detected in the current trial for RBC, HGB, and HCT. Due to a more frequent sampling compared to the cited studies, we demonstrated clear kinetics of hematological parameters related to parturition. The detection of maximum levels a few hours after calving for several parameters of the erythrogram could mark the end of their rise as discussed for the late gestation and the instant effects of parturition. Delivery is associated with immediate and marked effects on water and electrolyte balance of the cow, which could adulterate blood concentration profiles.

Although water intake could not be recorded around calving, it was obvious that cows reduced it as a typical reaction to birth $[35,39,40]$. This leads to a higher concentration of the blood cells and a seemingly increased number of erythrocytes. Furthermore, Chandra et al. [41] described that the plasma volume in humans decreased due to diuresis after parturition. The sudden drop in plasma volume might cause an apparent increase of RBC, HGB, and HCT. 
Besides supporting late fetal development and mammogenesis, the higher RBC at parturition assists the increased oxygen demand caused by the enhanced physical exertion during birth [42]. This view was supported by the increased respiration rate of the cows examined in the present study before calving [23]. In this context, the degree of HGB oxygenation and deoxygenation reached the maximum and minimum values, respectively. Oxygenated HGB tended to increase the rate of HGB autoxidation [43], and in parallel increase the affinity of partially oxygenated HGB for the RBC membrane. This could lead to an increased ROS formation at the membrane, resulting in peroxidative damaging [44] and consequently in a compromised erythrocyte functionality. To prevent damage, erythrocytes express, amongst others, SOD and GPx, which were upregulated prior to calving and paralleled by the increases in RBC and related parameters observed during this time. After calving, the levels of both enzymes declined rapidly to those observed at the beginning and at the end of the observation period (i.e., $\mathrm{d} 42$ ap and d $110 \mathrm{pp}$ in milk), suggesting that late fetal development and parturition induced a more pronounced erythrocytic oxidative stress when compared to the pp period [45]. A similar progression of antioxidant enzymes during the transition period of dairy cows has been described in previous studies [2,46], while Gaál et al. [47] documented an increase of SOD activity after calving. Compared to the defense system of the erythrocytes using antioxidative enzymes, the overall plasmatic non-enzymatic antioxidative capacity, measured as FRAP, indicated an increase within the first $d \mathrm{pp}$. The reason for this could be the increase in feed intake pp, as reported by Meyer et al. [23], which could lead to a better antioxidant supply. As an equivalent for reactive oxidative metabolites, the $\mathrm{dROM}$ was used in the present study, which increased simultaneously with FRAP. Urh et al. [48] also described an increase in dROM values within the first $d \mathrm{pp}$ and a decrease thereafter. This could be related to the increased feed intake after parturition. L-carnitine is described to protect the endogenous antioxidant defense system, including GPx and SOD, in human hepatocytes under cytotoxic conditions [49,50]. In a human clinical trial, Lee et al. [51] demonstrated that dietary L-carnitine $(1000 \mathrm{mg} / \mathrm{d}$ for 12 weeks) reduced the oxidative stress and increased the antioxidant enzyme activities significantly in patients with cardiovascular diseases, and Thangasamy et al. [52] described antioxidant effects of L-carnitine in aged rats. Little is known about the effect of L-carnitine administration on antioxidative systems in periparturient cows. However, the present study did not suggest modifying effects of L-carnitine supplementation under the tested conditions. Considering a close association between oxidative stress and membrane stability of erythrocytes might explain the failure of L-carnitine to influence the erythrogram. Similarly, Strasser et al. [12], Uluisik et al. [20], and Asadi et al. [53] could not detect an impact of a dietary L-carnitine supplementation on RBC, HGB, MCV, MCH, and MCHC in rats (150 and $75 \mathrm{mg}$ L-carnitine/ $\mathrm{kg}$ body weight dissolved in drinking water) and broilers (200 mg L-carnitine/ $\mathrm{kg}$ body weight). On the other hand, HCT levels in humans were found to be increased by L-carnitine supplementation, which positively influenced lipids of the cell membrane of erythrocytes, which could thereby be stabilized [54]. It has been suggested by in vitro studies that increased membrane stability was due to interactions of L-carnitine with the proteins of the cytoskeletal structures, and that L-carnitine affected the lipid and protein composition of biological membranes [6,55]. Further studies showed that clustering of human erythrocytes caused by fibrinogen was inhibited by L-carnitine [6,56]. This effect has not yet been investigated in dairy cows.

In contrast to the erythrogram, PLT and related parameters were influenced by Lcarnitine supplementation. In general, the number of PLT and PCT increased during the first few $\mathrm{d}$ after parturition, which was already described in other studies $[37,57]$ and discussed as a response to minor hemorrhaging caused by the calving. The higher concentration of PLT in L-carnitine supplemented cows within the first $48 \mathrm{~h}$ after parturition might be a hint of an improved membrane stability and, therefore, a reduced PLT destruction [12]. In in vitro studies with PLT, an improved membrane stability could be demonstrated after L-carnitine supplementation [17]. Furthermore, in vitro studies using human PLT demonstrated that L-carnitine addition interacted with arachidonic acid (AA) metabolism and 
incorporation into activated PLT $[18,19]$. It was shown that less AA was integrated into the phospholipid membrane and consequently less ROS were produced. Moreover, NADPH oxidases were inhibited [18]. However, the activity of the PLT in the current experiment was determined indirectly via the PLT indices. The MPV is an indicator for a change in form of PLT $[8,58]$ and PDW is a more specific marker of PLT activation. In the current study, the MPV did not change until three $\mathrm{d} p \mathrm{p}$ and was unaffected by L-carnitine. PDW remained unchanged over time and by L-carnitine supplementation. This might indicate that the production and activity of PLT were unaffected and supports the hypothesis that L-carnitine improved the membrane stability in these cells.

\section{Conclusions}

Dietary L-carnitine supplementation failed to modify the kinetics of the erythrogram as well as related indices in the transition period of cows. The high frequency of blood sampling during the first three $d \mathrm{pp}$ allowed for the observation of specific features of the kinetics of platelets and of the erythrogram, as well as related indices in this period critical for the later health of the cow.

The development of polycythemia ap appears to be triggered by the increased oxygen need due to fetal development, mammogenesis, parturition, and onset of lactation. It might be concluded that the endogenous synthesis of L-carnitine was sufficient for a physiological erythropoiesis and erythrocyte functioning.

The ap observed increase in erythrocytic antioxidative enzymes paralleled the increase in RBC without being influenced by L-carnitine supplementation. This further supports the conclusion that endogenous L-carnitine was sufficient and/or that erythrocytes do not rely on L-carnitine to the same extent as platelets. The results demonstrated that dietary L-carnitine supplementation affected the PLT and related parameters. According to the literature, this might be due to membrane stabilizing effects although these mechanisms require further elucidation for Bovinae.

Author Contributions: Conceptualization: S.D., J.F., K.H.; Formal Analysis: S.U.K.; Investigation: S.U.K., J.M., J.F., J.K., S.K., Resources: S.U.K.; Data Curation: S.U.K.; Writing Original Draft Preparation: S.U.K.; Review and Editing: S.U.K., J.M., J.F., J.K., S.K., U.M., K.H., S.D.; Visualization: S.U.K., J.M.; Supervision: J.F., S.K., S.D., K.H.; Project Administration: K.H., S.D.; Funding Acquisition: K.H., S.D. All authors have read and agreed to the published version of the manuscript.

Funding: This research was funded by German Research Foundation (DFG, 202989534).

Acknowledgments: The authors thank the co-workers of the Institute of Animal Nutrition and the co-workers of the experimental station of the Friedrich-Loeffler-Institute in Brunswick for their great support. Further thanks go to the German Research Foundation (DFG) for their financial support.

Conflicts of Interest: The authors declare no conflict of interest.

\section{References}

1. Găvan, C.; Retea, C.; Motorga, V. Changes in the hematological profile of Holstein primiparous in periparturient period and in early to mid lactation. Sci. Pap. Anim. Sci. Biotechnol. 2010, 43, 244-246.

2. Konvičná, J.; Vargová, M.; Paulíková, I.; Kovcáč, G.; Kostecká, Z. Oxidative stress and antioxidant status in dairy cows during prepartal and postpartal periods. Acta Vet. Brno 2015, 84, 133-140. [CrossRef]

3. Drackley, J.K.; Overton, T.R.; Douglas, G.N. Adaptations of glucose and long-chain fatty acid metabolism in liver of dairy cows during the periparturient period. J. Dairy Sci. 2001, 84, E100-E112. [CrossRef]

4. Jonsson, N.N.; Fortes, M.R.S.; Piper, E.K.; Vankan, D.M.; de Cisneros, J.P.J.; Wittek, T. Comparison of metabolic, hematological, and peripheral blood leukocyte cytokine profiles of dairy cows and heifers during the periparturient period. J. Dairy Sci. 2013, 96, 2283-2292. [CrossRef] [PubMed]

5. Cooper, M.B.; Forte, C.A.; Jones, D. Carnitine and acetylcarnitine in red blood cells. Biochim. Et Biophys. Acta Lipids 1988, 959, 100-105. [CrossRef]

6. Arduini, A.; Rossi, M.; Mancinelli, G.; Belfiglio, M.; Scurti, R.; Radatti, G.; Shohet, S.B. Effect of L-carnitine and acetyl-L-carnitibe on the human erythrocyte membrane stability and deformability. Life Sci. 1990, 47, 2395-2400. [CrossRef]

7. Kraft, W.; Dürr, U.M. Klinische Labordiagnostik in der Tiermedizin; Schattauer: Stuttgart, Germany, 2005. 
8. Budak, Y.U.; Polat, M.; Huysal, K. The use of platelet indices, plateletcrit, mean platelet volume and platelet distribution width in emergency non-traumatic abdominal surgery: A systematic review. Biochem. Med. 2016, 26, 178-193. [CrossRef]

9. Jenne, C.N.; Urrutia, R.; Kubes, P. Platelets: Bridging hemostasis, inflammation, and immunity. Int. J. Lab. Hematol. 2013, 35, 254-261. [CrossRef]

10. Chacko, B.K.; Kramer, P.A.; Ravi, S.; Johnson, M.S.; Hardy, R.W.; Ballinger, S.W.; Darley-Usmar, V.M. Methods for defining distinct bioenergetic profiles in platelets, lymphocytes, monocytes, and neutrophils, and the oxidative burst from human blood. Lab. Investig. 2013, 93, 690-700. [CrossRef]

11. Iuliano, L.; Colavita, A.R.; Leo, R.; Praticò, D.; Violi, F. Oxygen Free Radicals and Platelet Activation. Free Radic. Biol. Med. 1997, 22, 999-1006. [CrossRef]

12. Strasser, A.; Dedoyard, A.; Lohninger, A.; Niedermüller, H. 1-Carnitine 1-tartrate (LCLT) and dehydroepiandrosterone sulfate (DHEAS) affect red and white blood cells in aged Sprague-Dawley rats. Arch. Gerontol. Geriatr. 2007, 44, 325-336. [CrossRef] [PubMed]

13. Sordillo, L.M.; Aitken, S.L. Impact of oxidative stress on the health and immune function of dairy cattle. Vet. Immunol. Immunopathol. 2009, 128, 104-109. [CrossRef] [PubMed]

14. Schlegel, G.; Keller, J.; Hirche, F.; Geissler, S.; Schwarz, F.J.; Ringseis, R.; Stangl, G.I.; Eder, K. Expression of genes involved in hepatic carnitine synthesis and uptake in dairy cows in the transition period and at different stages of lactation. BMC Vet. Res. 2012, 8, 28. [CrossRef] [PubMed]

15. Ringseis, R.; Keller, J.; Eder, K. Regulation of carnitine status in ruminants and efficacy of carnitine supplementation on performance and health aspects of ruminant livestock: A review. Arch. Anim. Nutr. 2018, 72, 1-30. [CrossRef] [PubMed]

16. Gülçin, I. Antioxidant and antiradical activities of L-carnitine. Life Sci. 2006, 78, 803-811. [CrossRef]

17. Sweeney, J.D.; Arduini, A. L-Carnitine and Its Possible Role in Red Cell and Platelet Storage. Transfus. Med. Rev. 2004, 18, 58-65. [CrossRef]

18. Pignatelli, P.; Lenti, L.; Sanguigni, V.; Frati, G.; Simeoni, I.; Gazzaniga, P.P.; Pulcinelli, F.M.; Violi, F. Carnitine inhibits arachidonic acid turnover, platelet function, and oxidative stress. Am. J. Physiol. Heart Circ. Physiol. 2003, 284, H41-H48. [CrossRef]

19. Saluk-Juszczak, J.; Olas, B.; Wachowicz, B.; Glowacki, R.; Bald, E. L-carnitine modulates blood platelet oxidative stress. Cell Biol. Toxicol. 2010, 26, 355-365. [CrossRef]

20. Uluisik, D.; Keskin, E. The effects of L-carnitine on some hematological parameters in rats fed a cholesterol-rich diet. Biotech. Histochem. 2014, 89, 393-397. [CrossRef]

21. Goff, J.P.; Stabel, J.R. Decreased Plasma Retinol, $\alpha$-Tocopherol, and Zinc Concentration During the Periparturient Period: Effect of Milk Fever. J. Dairy Sci. 1990, 73, 3195-3199. [CrossRef]

22. Gessner, D.K.; Most, E.; Schlegel, G.; Kupczyk, K.; Schwarz, F.J.; Eder, K. Concentrations of retinol and tocopherols in the milk of cows supplemented with conjugated linoleic acid. J. Anim. Physiol. Anim. Nutr. 2015, 99, 1039-1046. [CrossRef] [PubMed]

23. Meyer, J.; Daniels, S.U.; Grindler, S.; Tröscher-Mußotter, J.; Alaedin, M.; Frahm, J.; Hüther, L.; Kluess, J.; Kersten, S.; von Soosten, D.; et al. Effects of a Dietary L-Carnitine Supplementation on Performance, Energy Metabolism and Recovery from Calving in Dairy Cows. Animals 2020, 10, 342. [CrossRef] [PubMed]

24. Paglia, D.E.; Valentine, W.N. Studies on the quantitative and qualitative characterization of erythrocyte glutathione peroxidase. J. Lab. Clin. Med. 1967, 70, 158-169. [PubMed]

25. Benzie, I.F.F.; Strain, J.J. The Ferric Reducing Ability of Plasma (FRAP) as a Measure of “Antioxidant Power": The FRAP Assay. Anal. Biochem. 1996, 239, 70-76. [CrossRef] [PubMed]

26. Regenhard, P.; Nakov, D.; Sauerwein, H. Applicability of a spectrophotometric method for assessment of oxidative stress in poultry. Maced. Vet. Rev. 2014, 37, 43-47. [CrossRef]

27. Akers, R.M. A 100-Year Review: Mammary development and lactation. J. Dairy Sci. 2017, 100, 10332-10352. [CrossRef] [PubMed]

28. Fandrey, J. Oxygen-dependent and tissue-specific regulation of erythropoietin gene expression. Am. J. Physiol. Regul. Integr. Comp. Physiol. 2004, 286, R977-R988. [CrossRef]

29. Moritz, K.M.; Lim, G.B.; Wintour, E.M. Developmental regulation of erythropoietin and erythropoiesis. Am. J. Physiol. 1997, 273, R1829-R1844. [CrossRef]

30. Haase, V.H. Hypoxic regulation of erythropoiesis and iron metabolism. Am. J. Physiol. Ren. Physiol. 2010, 299, F1-F13. [CrossRef]

31. Shao, Y.; Zhao, F.-Q. Emerging evidence of the physiological role of hypoxia in mammary development and lactation. J. Anim. Sci. Biotechnol. 2014, 5, 9. [CrossRef]

32. Götze, A.; Honnens, A.; Flachowsky, G.; Bollwein, H. Variability of mammary blood flow in lactating Holstein-Friesian cows during the first twelve weeks of lactation. J. Dairy Sci. 2010, 93, 38-44. [CrossRef] [PubMed]

33. Fleet, I.R.; Peaker, M. Mammary function and its control at the cessation of lactation in the goat. J. Physiol. 1978, 279, 491-507. [CrossRef] [PubMed]

34. Reynolds, C.K.; Aikman, P.C.; Lupoli, B.; Humphries, D.J.; Beever, D.E. Splanchnic Metabolism of Dairy Cows During the Transition From Late Gestation Through Early Lactation. J. Dairy Sci. 2003, 86, 1201-1217. [CrossRef]

35. Moretti, P.; Probo, M.; Cantoni, A.; Paltrinieri, S.; Giordano, A. Fluctuation of neutrophil counts around parturition in Holstein dairy cows with and without retained placenta. Res. Vet. Sci. 2016, 107, 207-212. [CrossRef] [PubMed]

36. Tharwat, M.; Ali, A.; Al-Sobayil, F. Hematological and biochemical profiles in goats during the transition period. Comp. Clin. Pathol. 2015, 24, 1-7. [CrossRef] 
37. Olmos, G.; Boyle, L.; Horan, B.; Berry, D.P.; Sayers, R.; Hanlon, A.; Mee, J.F. Effect of holstein-friesian genetic group on peripartum and early lactation haematological and acute phase proteins profiles, health and fertility. Animal 2009, 3, 1013-1024. [CrossRef] [PubMed]

38. Belić, B.; Cincović, M.R.; Davidov, I.; Lako, B.; Potkonjak, A.; Stančić, I. Periparturient hematological finding in dairy cows with uterus and udder inflammation. Serb. J. Agric. Sci. 2012, 61, 111.

39. Schäfers, S.; von Soosten, D.; Meyer, U.; Drong, C.; Frahm, J.; Tröscher, A.; Pelletier, W.; Sauerwein, H.; Dänicke, S. Influence of conjugated linoleic acids and vitamin $\mathrm{E}$ on biochemical, hematological, and immunological variables of dairy cows during the transition period. J. Dairy Sci. 2018, 101, 1585-1600. [CrossRef]

40. Klinkon, M.; Zadnik, T. Dynamics of red and white blood picture in dairy cows during the periparturient period. Comp. Haematol. Int. 1999, 9, 156-161. [CrossRef]

41. Chandra, S.; Tripathi, A.K.; Mishra, S.; Amzarul, M.; Vaish, A.K. Physiological changes in hematological parameters during pregnancy. Indian J. Hematol. Blood Transfus. 2012, 28, 144-146. [CrossRef]

42. Sharma, A.; Kumar, P.; Singh, M.; Vasishta, N.K. Haemato-biochemical and endocrine profiling of north western Himalayan Gaddi sheep during various physiological/reproductive phases. Open Vet. J. 2015, 5, 103-107. [PubMed]

43. Abugo, O.O.; Rifkind, J.M. Oxidation of hemoglobin and the enhancement produced by nitroblue tetrazolium. J. Biol. Chem. 1994, 269, 24845-24853. [PubMed]

44. Nagababu, E.; Gulyani, S.; Earley, C.J.; Cutler, R.G.; Mattson, M.P.; Rifkind, J.M. Iron-deficiency anaemia enhances red blood cell oxidative stress. Free Radic. Res. 2008, 42, 824-829. [CrossRef] [PubMed]

45. Bernabucci, U.; Ronchi, B.; Lacetera, N.; Nardone, A. Influence of Body Condition Score on Relationships Between Metabolic Status and Oxidative Stress in Periparturient Dairy Cows. J. Dairy Sci. 2005, 88, 2017-2026. [CrossRef]

46. Bühler, S.; Frahm, J.; Tienken, R.; Kersten, S.; Meyer, U.; Huber, K.; Dänicke, S. Effects of energy supply and nicotinic acid supplementation on serum anti-oxidative capacity and on expression of oxidative stress-related genes in blood leucocytes of periparturient primi- and pluriparous dairy cows. J. Anim. Physiol. Anim. Nutr. 2018, 102, e87-e98. [CrossRef]

47. Gaál, T.; Ribiczeyné-Szabó, P.; Stadler, K.; Jakus, J.; Reiczigel, J.; Kövér, P.; Mézes, M.; Sümeghy, L. Free radicals, lipid peroxidation and the antioxidant system in the blood of cows and newborn calves around calving. Comp. Biochem. Physiol. Part B Biochem. Mol. Biol. 2006, 143, 391-396. [CrossRef]

48. Urh, C.; Denißen, J.; Gerster, E.; Kraus, N.; Stamer, E.; Heitkönig, B.; Spiekers, H.; Sauerwein, H. Pro-and antioxidative indicators in serum of dairy cows during late pregnancy and early lactation: Testing the effects of parity, different dietary energy levels, and farm. J. Dairy Sci. 2019, 102, 6672-6678. [CrossRef]

49. Li, J.-L.; Wang, Q.-Y.; Luan, H.-Y.; Kang, Z.-C.; Wang, C.-B. Effects of L-carnitine against oxidative stress in human hepatocytes: Involvement of peroxisome proliferator-activated receptor alpha. J. Biomed. Sci. 2012, 19, 32. [CrossRef]

50. Binienda, Z.K.; Ali, S.F. Neuroprotective role of L-carnitine in the 3-nitropropionic acid induced neurotoxicity. Toxicol. Lett. 2001, 125, 67-73. [CrossRef]

51. Lee, B.J.; Lin, J.S.; Lin, Y.C.; Lin, P.T. Effects of L-carnitine supplementation on oxidative stress and antioxidant enzymes activities in patients with coronary artery disease: A randomized, placebo-controlled trial. Nutr. J. 2014, 13, 79. [CrossRef]

52. Thangasamy, T.; Subathra, M.; Sittadjody, S.; Jeyakumar, P.; Joyee, A.G.; Mendoza, E.; Chinnakkanu, P. Role of L-carnitine in the modulation of immune response in aged rats. Clin. Chim. Acta 2008, 389, 19-24. [CrossRef] [PubMed]

53. Asadi, H.; Sadeghi, A.; Eila, N.; Aminafshar, M. Carcass traits and immune response of broiler chickens fed dietary L-Carnitine, coenzyme Q10 and ractopamine. Braz. J. Poult. Sci. 2016, 18, 677-682. [CrossRef]

54. Sotirakopoulos, N.; Athanasiou, G.; Tsitsios, T.; Mavromatidis, K. The influence of l-carnitine supplementation on hematocrit and hemoglobin levels in patients with end stage renal failure on CAPD. Ren. Fail. 2002, 24, 505-510. [CrossRef] [PubMed]

55. Arduini, A.; Gorbunov, N.; Arrigoni-Martelli, E.; Dottori, S.; Molajoni, F.; Russo, F.; Federici, G. Effects of l-carnitine and its acetate and propionate esters on the molecular dynamics of human erythrocyte membrane. Biochim. Et Biophys. Acta (BBA) Biomembr. 1993, 1146, 229-235. [CrossRef]

56. Fritz, I.B.; Wong, K.; Burdzy, K. Clustering of erythrocytes by fibrinogen is inhibited by carnitine: Evidence that sulfhydryl groups on red blood cell membranes are involved in carnitine actions. J. Cell. Physiol. 1991, 149, 269-276. [CrossRef] [PubMed]

57. Orrù, L.; Abeni, F.; Catillo, G.; Grandoni, F.; Crisà, A.; De Matteis, G.; Carmela Scatà, M.; Napolitano, F.; Moioli, B. Leptin gene haplotypes are associated with change in immunological and hematological variables in dairy cow during the peripartum period. J. Anim. Sci. 2012, 90, 16-26. [CrossRef]

58. Schoene, N.W.; Guidry, C.A. Dietary soy isoflavones inhibit activation of rat platelets. J. Nutr. Biochem. 1999, 10, 421-426. [CrossRef] 